\title{
Narcotelenovelas e um relato de nação: aproximações da cultura e da política colombianas através do estudo de recepção de Escobar, el patrón del mal, por audiências brasileiras ${ }^{1}$
}

\section{Simone Maria Rocha²}

Recibido: 2016-05-20

Enviado a pares: 2016-06-02
Aprobado por pares: 2016-07-18

Aceptado: 2017-08-03

DOI: 10.5294/pacla.2018.21.1.4

\section{Para citar este artículo / to reference this article / para citar este artigo}

Rocha, S. M. (2018). Narcotelenovelas e um relato de nação: aproximações da cultura e da política colombianas através do estudo de recepção de Escobar, el patrón del mal, por audiências brasileiras. Palabra Clave, 21(1), 58-85. DOI: 10.5294/pacla.2018.21.1.4

\section{Resumo}

Este artigo parte do pressuposto da relevância cultural da televisão, segundo o qual suas narrativas são centrais no que diz respeito ao conhecimento da história, da política, de relatos de nação e de uma memória recente de nossos países latino-americanos. Apresento os resultados de uma investigação que demonstra, através da realização de grupos de discussão, as interpretações de telespectadores brasileiros da narcotelenovela colombiana Escobar, el patrón del mal com o objetivo de entender como foi construída a recente história e os conflitos políticos e culturais daquela sociedade desde um produto televisivo. Concluo que os sentidos atribuídos pelos participantes dos grupos revelou aspectos importantes deste papel da televisão em nossas sociedades. A narcotelenovela os fez ver os meandros de uma problemática instaurada de modo profundo na cultura e na política colombianas, os auxiliou na apreen-

1 Agradeço ao Conselho Nacional de Desenvolvimento Científico e Tecnológico (CNPq) o apoio financeiro. E um agradecimento especial deve ser feito a Dayanne S. Campos, Daniel Matos, Gober Gomez e Isabelle Chagas, pelo auxílio em todas as fases de realização da pesquisa que deu origem a este texto.

2 orcid.org/0000-0002-4415-8745. Universidade Federal de Minas Gerais/UFMG. Brasil. simonerocha@ufmg.br 
são crítica dos fenômenos e acontecimentos de nossa própria realidade e os fez ver que nossas sociedades latino-americanas desenvolvem, para o bem ou para o mal, suas estratégias próprias de entrada na modernidade.

\section{Palavras-chave}

Colômbia; cultura política; narcotelenovela; Pablo Escobar; grupo de discussão (Fonte: Tesauro da Unesco).

\section{Narcotelenovelas y un relato de nación: aproximaciones a la cultura y de la política colombianas a través del estudio de recepción de Escobar, el patrón del mal, por las audiencias brasileras}

\section{Resumen}

Este artículo parte de la supuesta relevancia cultural de la televisión, según la cual sus narrativas son centrales con respecto al conocimiento de la historia, de la política, de los relatos de nación y de una memoria reciente de nuestros países latinoamericanos. Presento los resultados de una investigación que demuestra, a través de la realización de grupos de discusión, las interpretaciones de los telespectadores brasileros de la narcotelenovela colombiana Escobar, el patrón del mal con el objetivo de entender cómo fue construida la historia reciente y los conflictos políticos y culturales de esa sociedad desde un producto televisivo. Concluyo que los sentidos atribuidos por los participantes de los grupos revelaron aspectos importantes de este rol de la televisión en nuestras sociedades. La narcotelenovela les hizo ver los meandros de una problemática profundamente arraigada en la cultura y en la política colombianas, así como influyó en la comprensión crítica de los fenómenos y acontecimientos de nuestra propia realidad y les hizo ver que nuestras sociedades latinoamericanas desarrollan, para bien o para mal, sus propias estrategias de introducción en la modernidad. 


\section{Palabras clave}

Colombia; cultura política; narcotelenovela; Pablo Escobar; grupo de discusión (Fuente: Tesauro de la Unesco).

\section{Narco-Telenovelas and an Account of the Nation: Approaches to Colombian Culture and Politics through a Study of the Reception of Escobar, el Patrón del Mal by Brazilian Audiences}

\section{Abstract}

This paper starts from the idea of the cultural relevance of television, according to which its narratives are central to knowing the history, politics, the stories about the nation and a recent memory of our Latin American countries. Here, I present the results of a research that illustrates, through development groups, how Brazilian viewers interpret Colombian narco-telenovela Escobar, el Patrón del Mal, with the aim of understanding how recent history was built, as well as the political and cultural conflicts of that society from a television product. My conclusion is that the meanings attributed by the participants of the groups revealed important aspects of this role of television in our societies. The narco-telenovela faced them with the intricacies of a problem that is deeply embedded in Colombian culture and politics; it also helped them to understand the phenomena and events of our own reality from a critical standpoint and showed them that our Latin American societies develop, for better or worse, their own strategies of entry into modernity.

\section{Keywords}

Colombia; political culture; narco-telenovela; Pablo Escobar; discussion group (Source: Unesco Thesaurus). 


\section{Introdução}

Entre 2009 e 2012, a rede de televisão colombiana TV Caracol produziu e exibiu a narrativa de ficção seriada Escobar, el patrón del mal, baseada nos principais momentos da vida do maior narcotraficante da história daquele país, Pablo Emilio Escobar Gaviria. Considerada uma realização ambiciosa da tevê colombiana, a série alcançou audiências significativas desde sua estreia e, para Carlos Moreno, seu diretor, um dos principais propósitos da nova série de televisão "es ayudarles a las nuevas generaciones a entender mejor al personaje, sus motivaciones y las consecuencias de sus actos” (Robledo, 2012).

O roteiro para televisão, escrito por Juan Camilo Ferrand, partiu de uma adaptação do romance La parábola de Pablo: auge y caída de un gran capo del narcotráfico, do jornalista e ex-prefeito de Medellín Alonso Salazar, e abordou a vida de Escobar desde sua infância, passou por sua juventude, suas primeiras incursões no mundo do crime, chegou a meados dos anos de 1970, quando começou seu envolvimento com o narcotráfico, e terminou com sua morte em 1993. No romance, estão presentes os universos cultural, religioso e familiar como elementos de fundo da vida de Pablo. Ele enfrentou a tudo e a todos que tentaram impedir o crescimento de seu negócio; burlou fronteiras, criou rotas, exportou toneladas de cocaína aos Estados Unidos e à Europa, formou o Cartel de Medellín e chegou ao parlamento nacional. Ao ser denunciado pelo então ministro da Justiça Rodrigo Lara Bonilla, o capo iniciou uma guerra frontal contra o Estado assassinando, intimidando e aterrorizando a sociedade colombiana. Matou juízes, jornalistas, ministros e políticos, e impôs seu poder criminoso, sobretudo, àqueles que defendiam a extradição, a única arma da qual dispunha o Estado para persegui-lo e a única por ele temida.

Não temos a pretensão de pôr em cheque a veracidade dos fatos narrados na série sobre a controversa figura de Pablo Escobar, considerado um inimigo dos governos dos Estados Unidos e da Colômbia, e um herói para muitos em Medellín. Tampouco é objetivo de nossa pesquisa averiguar em que medida essa produção televisiva foi fiel aos diversos relatos literários, jornalísticos, documentais, dentre outros os quais tomou por base. Partimos da importância cultural que a televisão e seus produtos têm em 
nossas sociedades nas quais muitas vezes o acesso a informações e relatos de nossas histórias ainda nos chegam por esse meio. A vida social contemporânea é marcada por uma ampla inserção das mídias e, no nosso caso específico, a televisão rege as interações comunicativas no sentido de que está sempre interpelando os sujeitos, convidando-os a serem seus interlocutores, a se relacionarem com o "comum" representado.

Ademais, Escobar, el patrón del mal, mostrou ser uma fórmula bemsucedida que interpelou e interpela as pessoas e as faz (re)viver um período difícil e impactante na história colombiana. Entendemos que um produto como esse não apenas relata, mas também colabora na construção de uma memória histórica recente daquele país bem como de sociedades que possuem forte tradição oral e nas quais a modernidade e suas consequências chegaram através dos meios de comunicação, em especial a televisão, e não dos livros (Herlinghaus e Walter, 1994; Martín-Barbero, 1987).

A partir da relevância da mídia televisiva, da figura de Pablo Escobar e do narcotráfico na história recente da Colômbia, propomo-nos a empreender uma pesquisa que alcance as interpretações realizadas por audiências brasileiras acerca dessa ficção seriada. Para isso, contamos com opiniões emitidas em grupos de discussão realizados com o objetivo de entender qual é a história política e cultural da sociedade colombiana que as audiências brasileiras constroem com base em Escobar, el patrón del mal.

\section{Narcotelenovela ${ }^{3}$}

Para Omar Rincón $(2013,2009)$, a narcocultura espalhou sua simbologia e seus modos de ser pelas sociedades latino-americanas, e inspirou formas e manifestações na linguagem, na estética, na arquitetura até chegar à televisão.

3 Sabemos das distinções havidas entre os gêneros da telenovela e da série dramática. Jesús Martín-Barbero aborda tal questão tanto em Hegemonia do ver (2004) quanto em Televisión y literatura nacional (2000). Para este texto, argumentamos que, no Brasil, os produtos que tratam da representação do narcotráfico são apresentados como narcotelenovela, o que nos fez considerar sob esse termo todas as ficções seriadas televisivas que tratam dessa temática. Um estudo posterior e mais detido no produto e de sua dimensão audiovisual pretende ser a continuidade desta pesquisa. 
Recentemente, os telespectadores colombianos têm acompanhado a proliferação de telenovelas e séries que abordam essa temática complexa e delicada que vem atravessando a história do país nos últimos 30 anos. Assumimos que o ponto de partida desses produtos pode ser identificado com a produção e a exibição de La viuda de la mafia (RCN, 2004). Desde então, outras foram lançadas como Sin tetas no hay paraíso (TV Caracol, 2006), El cartel de los sapos (TV Caracol, 2008), El Capo (RCN, 2008 e 2012), Las muñecas de la mafia (TV Caracol, 2009), Rosario Tijeras (RCN, 2010), Escobar, el patrón del mal (TV Caracol, 2012) e Tres Caínes (RCN, 2013).

Tais produções visibilizam e inserem na esfera pública um tema muito sensível na sociedade colombiana, além de gerarem debates em torno de seus conteúdos, de seu tratamento e da ênfase a certas personagens e questões. Para Felipe Neira e Fabio López de la Roche, sempre que surge uma produção sobre o tema "[...] ha emergido una discusión en la sociedad que interroga e interpela estas ficciones con diversos puntos de vista en la que se enfocan sus dimensiones éticas, estéticas, poéticas, políticas, históricas, sociales o culturales" (2014, p. 2). Várias dessas controvérsias revelam posições para as quais o melhor seria esquecer o passado e que tais produtos acabam por promover uma apologia ao crime e uma imagem negativa da Colômbia; já outras defendem que o passado precisa ser revisto, criticado e conhecido para que não se repita no presente. Para López de la Roche $(2014)^{4}$, uma questão relevante sobre essas narcotelenovelas (a menos no que diz respeito ao seu funcionamento dentro do contexto colombiano) se refere a que, para a maioria dos colombianos que não leem jornais diariamente ou livros de história nem pertencem ao mundo da cultura letrada, tais narrativas, muitas vezes, constituem-se na única possibilidade de conhecimento da história recente do país. Tais produtos ficcionais, nos quais a montagem televisiva sobrepõe registros jornalísticos documentais com materiais ficcionais, devem merecer uma crítica sistemática por parte de historiadores e outros cientistas sociais.

4 Trecho retirado de uma das sessões do seminário "Comunicação, Cultura e Política na América Latina: elementos para análise cultural e político-cultural comparado”, ministrado pelo professor Fabio López de la Roche (2014), diretor do Instituto de Estudos Políticos e Relações Internacionais da Universidade Nacional da Colômbia. 


\section{Para adentrar o objeto: a criação do evento narrativo}

Uma das dificuldades em se trabalhar com produtos televisivos diz respeito ao volume significativo do material em questão. Nesse sentido, as unidades de análise nem sempre são precisas e, muitas vezes, o que os autores adotam são trechos (como cenas, sequências, capítulos ou episódios) de uma narrativa. No caso de nossa investigação, nenhuma dessas unidades apresentou-se como satisfatória no que tange à reflexão proposta por este trabalho. Diante dessa dificuldade, mas convictos de que a visão do conjunto seria a mais produtiva para a questão que apontamos neste texto, optamos por adotar o que chamamos de "eventos narrativos" como forma de adentrar no material. Esses eventos compõem uma trama (ou uma subtrama) e poderiam ser traduzidos pelos acontecimentos, pelas ações que garantem o desenvolvimento da história, como casamentos, romances, negociações empresariais, traições, disputas de poder etc. Um evento pode ou não durar vários capítulos e, em função das características do consumo de narrativas seriadas televisivas, necessitar do recurso da redundância (Thompson, 2003). Acompanhá-lo permite ao analista visualizar o entrelaçamento das tramas, o uso de indicadores temporais claros e a inserção de causas pendentes para a devida articulação de sequências separadas temporalmente (Rocha, Alves e Oliveira, 2013).

Assim, o trecho que recriamos, e que foi apresentado aos grupos, diz respeito a problemática, reverses e acontecimentos em torno de um possível acordo de extradição entre a Colômbia e os Estados Unidos. Essa escolha se deu não só porque tal tema foi o elemento catalisador dos ocorridos na história, mas também por estar presente, de modo transversal, em boa parte da narrativa. Após assistir aos 74 capítulos que fizeram parte da versão exibida no Brasil, a equipe editou um vídeo de aproximadamente 40 minutos denominado "evento da extradição".

\section{Um contexto instaurado para a troca reflexiva: o grupo de discussão}

Em virtude das condições de realização desta pesquisa (em um momento posterior ao da exibição da narcotelenovela no Brasil, e por se tratar 
de uma temática específica e não de consumo televisivo), optamos pela metodologia dos grupos de discussão que são basicamente entrevistas em grupo, cujo foco reside na interação dos participantes, e não no mero intercâmbio de perguntas e respostas entre o pesquisador e os integrantes. A interação entre os componentes está baseada em tópicos específcos que são trazidos pelo pesquisador que geralmente assume o papel de moderador da discussão (Morgan, 1997, p. 2) $)^{5}$. Assim, nos grupos, há o uso explícito da interação entre os presentes para produzir material de análise, pois, para David Morgan (1997), a interação gerada no encontro de experiências e vozes singulares é a fonte de dados, fazendo com que o método se autossustente.

O que há de específico nessa técnica? Morgan salienta o efeito de grupo, ou seja, o fato de que "os participantes fazem perguntas uns aos outros e explicam suas posições de forma recíproca" (1997, p. 139). Essa habilidade de observar a extensão e a natureza do acordo e do desacordo entre os participantes é algo único dessa dinâmica.

Os grupos focais provêm a oportunidade de observar os participantes conduzindo seus próprios testes discursivos, negociando sentidos, confirmando ou desafiando modos apropriados de percepção. (Lunt e Livingstone, 1996, p. 88 e 96)

Para o entendimento desta pesquisa, o grupo de discussão pode ser visto como uma mediação capaz de incentivar a produção de sentido em situações de recepção coletiva e evidenciar processos políticos de questionamento de representações e conhecimento de realidades distintas. $\mathrm{Na}$ condução dos grupos formados, buscamos avançar para além da ideia do receptor ativo e articulá-la com práticas político-culturais que motivam questionamentos, apropriações reflexivas, construção de conhecimento e crítica a partir do universo simbólico difundido pelos media, sobretudo

5 O grupo é focado no sentido que envolve algum tipo de atividade coletiva, como ver um filme, examinar uma mensagem ou simplesmente debater um conjunto específico de questões. O pesquisador pode trabalhar com grupos preexistentes ou selecionar os participantes de modo aleatório; ele deve realizar quantos grupos julgar produtivo para a pesquisa, sem desconsiderar um "ponto de saturação", que ocorre quando as histórias e os depoimentos começam a se repetir. A utilização dessa técnica prima pela qualidade das discussões e das relações construídas em um pequeno espaço de tempo e não pela quantidade. Para uma discussão mais detalhada, ver Morgan (1997). 
quando estes veiculam representações de sociedades distintas das nossas, perpassadas por conflitos e guerras internas, como é o caso da Colômbia. Ao constituir um grupo, interessa-nos saber como os participantes produzem conhecimento daquelas representações ali expostas e da realidade que elas configuram, e como tecem comparações com sua própria realidade.

Importante esclarecer, ainda, que não nos interessa defender o uso dos grupos de discussão como um método quase etnográfico ou quase naturalista, mas sim ressaltar a capacidade que apresentam de recriar situações de conversação cotidiana, de ocasiões sociais em que as habilidades críticas dos participantes emergem no momento em que se encontram reunidos para trocarem experiências e argumentos acerca de um determinado tema ou assunto. Por isso, acreditamos que, em vez de nos preocuparmos com a não naturalidade da situação construída, é mais proveitoso usar o grupo de discussão para encorajar as pessoas a se engajarem umas com as outras, a expressarem verbalmente suas visões de mundo e a descortinarem estruturas cognitivas que antes se encontravam desarticuladas.

Foram realizados cinco grupos durante os meses de março e abril de 2015: quatro em Belo Horizonte (estado de Minas Gerais) e um em Natal (estado do Rio Grande do Norte). Seguindo recomendações da literatura, cada grupo tinha entre 5 e 10 pessoas e sempre com algum elemento que garantisse homogeneidade: a) estudantes universitários de 20 a 25 anos (Grupo Universidade Federal de Minas Gerais - UFMG); b) profissionais liberais entre 22 e 30 anos da região de Venda Nova, em Belo Horizonte (Grupo Venda Nova); c) membros de uma mesma família e profissionais liberais, entre 50 e 58 anos (Grupo Família Belo Horizonte - BH); d) professores universitários da cidade de Natal, Rio Grande do Norte (Grupo Natal); e) educadores sociais, funcionários da Prefeitura de BH que atuam junto às famílias e às pessoas com deficiência, a maioria entre 20 e 30 anos (Grupo Educadores Sociais). Os participantes foram indicados por números, segundo sua ordem de participação nos grupos. Os números foram adotados para manter em sigilo a identidade de cada um.

A equipe elaborou um roteiro semiestruturado com o objetivo de guiar as discussões. Assim, ao considerar que Escobar, el patrón del mal tem 
se mostrado uma fórmula bem-sucedida que interpela as pessoas e as faz (re) viver uma época difícil e impactante da história da Colômbia, elaboramos as seguintes perguntas norteadoras da pesquisa: qual é a história política e cultural da sociedade colombiana que as audiências brasileiras constroem a partir dessa narcotelenovela? Como o narcotráfico tem permeado e se tornado presente naquela realidade? Como a narcotelenovela recria esse período segundo audiências não colombianas e que, muitas vezes, desconhecem tais eventos históricos? Quais mediações desempenham importante papel nesse processo de construção de sentido?

Os subtemas desenvolvidos a fim de estruturar a discussão foram:

- como vê a presença da polícia no conflito?

- como são as relações de Escobar e do narcotráfico com os políticos?

- $\quad$ qual é o papel da mídia nesse contexto ${ }^{6}$ ?

- como entendeu a relação com os Estados Unidos?

- como enxerga a presença do narcotráfico?

- a religião e a família são fatores importantes?

Para apresentar os resultados alcançados, criamos três categorias de análise a partir de aspectos que se revelaram recorrentes em todos os grupos. Foram elas: a) a "ausência" da droga versus a "presença" do narcotráfico; b) institucionalidade versus narcotráfico; c) ver a Colômbia e pensar o Brasil... ou narcotráfico e microtráfico.

\section{A "ausência" da droga versus a "presença" do narcotráfico}

Muitos participantes dos grupos notaram que a narrativa não priorizou a presença da droga tanto em termos de sua produção quanto de seu uso. Ainda

6 Não abordaremos tal aspecto na análise tendo em vista que a mídia foi vista de formas muito díspares, o que nos impediu de agrupar as falas segundo uma categoria que estruturasse a reflexão. Em alguns momentos, a mídia exercia papel quase pedagógico; em outros, os meios adquiriam voz de autoridade, exercendo pressão e vigilância. Também tiveram percepções ligadas à ideia de manipulação, parcialidade e defesa de interesses específicos, e não exatamente à de interesses e questões de natureza pública. Por último, a mídia apareceu ainda como uma instituição fraca, coagida, sem voz e ameaçada. 
que nos primeiros episódios tenham apresentado sequências que mostraram a produção da cocaína em Traquilandia, de fato, esse não foi um elemento presente de maneira significativa.

1. [...] em nenhum momento a gente viu drogas.

2. É. Isso é que eu senti falta. Fala sobre o narcotráfico, mas sem mostrar o produto. Em qualquer outro filme sobre drogas você realmente vê muitas drogas, eu só vi as armas.

3. Nem o uso de drogas também.

4. Eu acho que não é feito em forma de apologia, é feito em forma de retratação.

2. Quando a Globo decupou, eram mais de 100 episódios, ela cortou várias cenas. Será que as cenas que a gente não viu foram cortadas?

5. Eu acho que talvez seja uma questão de foco mesmo.

2. É uma coisa mais intelectual, né? O aviãozinho ${ }^{7}$ não aparece. (Grupo UFMG)

1. Ah, a droga, em si, ela aparece, ou não? Ou ela é só falada mesmo? Não apareceu nada dela, e tal, como eles mandam [...]

4. A movimentação $[. .$.

1. É, a movimentação da mercadoria em si.

Moderadora. Vocês acharam que o produto em si não apareceu?

6. Porque condensou muito, né, 75 horas em quantos minutos?

Pesquisadora. Mas [o vídeo] é representativo.

1. É, porque se fala de um produto, de uma droga, e aí ela, em momento nenhum ela é vista.

5. Não é mostrado nem operações de tráfico, nem de consumo. (Grupo Família $\mathrm{BH}$ )

7 “Aviãozinho" ou "avião" corresponde a um dos cargos existentes na hierarquia do tráfico de drogas no Brasil, ocupado principalmente por crianças e adolescentes e que tem como função transportar drogas e armas. 
Durante as discussões, duas foram as razões pelas quais pudemos perceber a ausência das drogas. A primeira diz do modo como o narcotráfico aparece como uma empresa, um negócio, uma atividade ou trabalho como outro qualquer. Os participantes disseram que é algo naturalizado, que os cidadãos poderiam escolher "seguir carreira de narcotraficante" como se escolhe ser médico, professor, advogado.

1. Para mim foi o fato dele entender que ele era um empresário, que a atividade dele era correta, o fato que economicamente ele está ganhando muito dinheiro. Ele fala que o problema dele não é social, é econômico, o dinheiro que ele está ganhando, tanto que ele faz uma comparação que com o cigarro e o álcool não é problema, eles pagam impostos e ele não paga.

2. Também tive essa impressão. (Grupo Educadores Sociais)

1. Como é uma terra sem lei, parece que é uma coisa [...]

2. Então nota-se a tranquilidade do próprio Pablo Escobar, e o que que parece, parecia ser uma pessoa normal, conversando com os companheiros dele ali, como se fosse uma coisa normal, ele vivendo ali, na casa dele, certamente com mulher e tudo.

1. Como se fosse uma empresa.

2. Uma empresa normal, uma coisa, né, que funciona, então é essa coisa que acontece mesmo [...]

3. [...] É uma empresa mesmo, e manda mesmo, e cala quem eles querem, e manipula todo mundo, e é todo mundo misturado, é polícia, é bandido, é governo, é político, e já fiquei olhando mais esse lado [...] (Grupo Família BH)

Dentro dessa visão, os personagens precisam ser entendidos não apenas como criminosos, mas também como força de trabalho, pois cada um tem seu posto e sua função. Como numa fábrica, estão encadeados em seu posto de trabalho. Esse princípio é demonstrado em toda a narcotelenovela: o narcotráfico é um negócio e funciona como uma empresa. Ao menos assim o compreendem Pablo Escobar e seus sócios. Evidentemente, não estamos nos referindo às regras normais de uma prática trabalhista 
(descansos regulares, proteção contra acidentes, horas extras). Tais regras são ignoradas pelos próprios empregados quando dizem: "eu simplesmente faço meu trabalho". Colocar-se em risco é condição inerente a esse ofício.

Nesse contexto, chamou a atenção dos participantes certo modo trivial pelo qual a morte era tratada. Era como se matar e morrer fizessem parte desse negócio.

2. E ele é muito despreocupado. Eu fiquei assustado com essa extrema liberdade do próprio Pablo, no negócio do filho dele. Ele tá falando de matar o cara, no aniversário do filho dele e tá totalmente despreocupado. Não tem ninguém vigiando, tá tranquilão.

5. Sim, na hora do comício quando eles tiram e mostram a arma. A arma é enorme. Aí eles vão, fazem o sinal da cruz e vai todo mundo espalhar pra matar. Mas é uma coisa assim tão tranquila.

2. É o cotidiano, né? É ordinário.

4. Eu achei até fora de lugar na hora que eles tão falando no walk-talk que eles tão falando por código. Mas, gente, tava tudo tão explícito, por que eles tão falando por código. Antes era tudo tão naturalizado.

6. [No caso do Galán] ele mudou de um ponto de vista, uma estratégia, e banaliza, negocia a vida das pessoas, de uma forma, uma tranquilidade, [...] mantém aquela calma, foi para a festa do filho, de primeira comunhão [...] isso me assusta [...] a maldade do ser humano, você via um presidente angustiado, na hora dele assinar, pensando se ia assinar, [porque] lógico que isso tem um objetivo, são vidas nas mãos de quem toma decisões. Mas a decisão de Pablo é como se... [ele dissesse] “me dá um copo de água?” E aí a gente resolve o problema da minha sede. [...] Assim, essa foi minha impressão geral, eu acho que a gente está banalizando esse mal, e a gente tem que ter esse cuidado, para a gente não banalizar. (Grupo Educadores Sociais)

Outro ponto de apoio a essa interpretação está relacionado aos sentidos e às visões de mundo compartilhados na chamada cultura paisa, típica da 
região que abarca os departamentos ${ }^{8}$ Antioquia, Caldas, Quindío e Risaralda, na qual Pablo cresceu e desenvolveu suas atividades. Trata-se de uma cultura regionalista, de caráter conservador, endogâmica e muito católica, pois, embora fundada por descendentes judeus, estes eram convertidos em novos cristãos e professavam a fé católica. Em termos econômicos, um dos adjetivos que melhor caracteriza essa cultura seria o empreendedorismo. A cultura paisa compartilha um valor segundo o qual o importante é fazer dinheiro a qualquer custo. Isso pode ser percebido pelo modo como a mãe de Escobar lida com a questão e ensina tais valores ao filho. Para ela: "meu filho só quer conseguir dinheiro, porque um homem sem dinheiro vive muito triste e mal”. Em vários episódios, após se reunir com os demais membros do Cartel de Medellín, Pablo dizia, "vamos parar de conversa e fazer o que a gente sabe fazer: plata”. Ao refletir e escrever sobre a prática assassina de jovens garotos, moradores da cidade de Medellín, que fizeram da atividade de matar por dinheiro seu modo de vida, Alonso Salazar aponta para uma cultura sincrética surgida do encontro de três outras fontes culturais: a cultura da modernização, a cultura maleva e a cultura paisa. Sobre essa última, o autor faz

Un planteamiento atrevido: la cultura paisa es una cultura de colonización. Esa es su razón de ser, su fuerza y su funcionalidad. Una cultura, de colonización y de convivencia. Es una cultura estructurada para abrir tierras, para conseguir plata, o en fin, para hacer lucro. [...] En el caso de los paisas esta ambigüedad es muy clara. Una cosa es el código ético formal y otra muy distinta el código de la vida. Ahí vale es la astucia, la audacia, el ser avispado, despierto: El vivo vive del bobo [...]. Si el objetivo es conseguir plata, no importa que en este propósito haya que contrariar alguna norma ética o religiosa. Antioquia ha sido tradicionalmente pueblo de contrabandistas. Parte de las familias de la tradicional aristocracia hicieron su fortuna en actividades ilegales sin que ello mortificara enormemente a la sociedad paisa. Y sectores de la élite paisa y colombiana toleraron durante largos años la mafia. (Salazar, 1991, p. 53)

Esses elementos podem nos auxiliar na compreensão do modo como, em sua "ética peculiar", Pablo Escobar considerava imoral roubar ao erário público e nada desonroso ser um próspero exportador de cocaína.

8 Os departamentos compõem a divisão político-administrativa da República da Colômbia. Equivalem aos estados brasileiros. 
A segunda razão atribuída à ausência da droga esteve ligada ao que a literatura sobre o tema chamou de narcopolítica praticada pelas personagens. Para muitos deles, pareceu clara a escolha do foco narrativo da narcotelenovela: expor o modo pelo qual o narcotráfico está arraigado e aderido na estrutura social e política colombianas. Expressões como "a política da droga", os "bastidores da droga”, dentre outras, foram acionadas como forma de se explicitar esse aspecto narrativo. Não se via a produção, não se via o consumo, porque a atenção estava posta nos meandros políticos, econômicos e sociais da presença do narcotráfico. Pablo Escobar não só logrou um posto da política formal, mas também se relacionou com vários políticos, financiou campanhas, apoiou famílias e comunidades pobres, além de ter o apoio de sua família.

\section{Institucionalidade versus narcotráfico}

Sob o vocábulo narcopolítica, estão incluídas várias dimensões da problemática. A principal delas está ligada ao que poderíamos chamar de fragilidade institucional. Muitos participantes foram enfáticos: o Estado mostra-se fraco, débil e incapaz de lidar com problema. As razões foram variadas: corrupção, incompetência, dependência dos Estados Unidos, ausência da polícia. Quando perguntados sobre a relação entre narcotráfico e política, os grupos assim se manifestaram:

4. É muito naturalizada, é uma coisa comum assim. Tá todo mundo falando sobre isso, a política, a mídia. É uma coisa corriqueira.

3. Mas eu acho que isso meio que responde essa coisa de como você vê a política. A gente vê o narcotráfico na política, nessa série. A gente não vê na base, a pessoa comprando.

4. É exatamente isso que eu ia falar, o narcotráfico, essa ausência das drogas é significativa, porque eles mostram justamente [...] a estrutura do tráfico por dentro, mas a força social que isso tem e como que isso mexe politicamente.

2. É como se fizesse um recorte, o que a gente vai mostrar aqui?

4. Exatamente. Não como apologia assim, mas o narcotráfico como força motriz, como estrutura. 
2. Mais as suas consequências; o que realmente é ele.

6. Não só o narcotráfico, mas acho que a violência também. Não mostra a bala entrando, mostra por trás. A violência é muito comentada, mas não aparece tanto. (Grupo UFMG)

3. Mostra a parte empresarial, a negociação, a influência na política, né?...

2. Pois é, além de não ter mostrado, como os participantes 1 e 5 falaram, a venda da droga, a forma que remete pro exterior, ou que seja o consumo lá dentro, e tudo, né, não mostrou, também, a consequência disso $[\ldots]$

1. É como se eles tivessem longe do final, do final da droga, né, ou seja, da ponta.

Moderadora. Você falou da política da droga?

1. É, é essa parte que a gente vive aqui, que é o consumo, é como se lá fosse a política da droga, como se fosse um congresso nacional, sabe? [risadas]

Moderadora. Entendi.

1. Lá a coisa é pensada, e tal, deve pensar como que vai produzir, pra onde vai mandar, e tal, e a gente aqui, o resto do mundo, recebe, né, e vai se danar com as consequências dela, né?

3. É, lá é a negociação, né, a produção, é a empresa mesmo, é a pressão política. (Grupo Família BH)

Mesmo quando o Estado mostrou-se empenhado em encontrar alguma solução, mesmo quando havia políticos envolvidos e comprometidos com o extermínio do narcotráfico no país, como foi o caso do senador Luis Carlos Galán, as alternativas encontradas apontavam nessa direção: um Estado frágil e acuado que via na extradição a única forma de lidar com o problema enfrentado pela Colômbia. Tal característica pode ser percebida na relação de dependência com os Estados Unidos.

3. $[. .$.$] Eu achei que o filme ressaltou o lado da política totalmente con-$ trário a isso, porque, na verdade, o tráfico em si, ele é o que financia. 
[... E E aqui nós estamos vendo uma história de um político que tá tentando tirar uma pessoa, um traficante de renome, um traficante que domina todo um país, a ponto de matar tudo quanto é pessoa que encontrar no seu caminho. A gente vê o lado de político que está fazendo com que esse traficante saia dali.

4. Mas também, tira do seu país e joga no outro país.

3. Não, mas ele quer levar pros Estados Unidos, lá ele será julgado.

4. Sim, mas se a gente for raciocinar pela base de [...] Eu não sei o nome [...] De um traficante também forte que tá preso e teve que fazer plásticas, mudar de nome etc. Esse cara foi um cara que foi achado no Brasil e ficou aquele lenga lenga. Manda pro país, julga, não julga. A gente sabe que a lei nos Estados Unidos é totalmente diferente da nossa. [... A Colômbia de certa forma estava mostrando no filme que queria isso aí. Queria? Queria. Mas por quê? Porque ele ia responder pelos crimes dele lá. E dentro da Colômbia a própria justiça não tinha como lidar com o cara. Então, tipo assim, o problema é meu, mas eu vou mandar pra lá porque lá eles vão resolver.

5. [Interrompe] Os caras não têm estrutura pra isso.

3. Não, não é estrutura. Uma coisa é você ter provas, é você ter substância pra pegar e falar assim "não, agora você vai ser preso". [...] Porque lá nos Estados Unidos tinha prova, lá na Colômbia não tinha. Não tinha um processo, não tinha prova. Tudo era por meio de terceiros. Você achava que era ele, mas onde você tinha certeza? (Grupo Venda Nova)

1. É, a Polícia Civil estava ao serviço do poder americano.

6. Porque senão era para ser julgado na Colômbia, o Estado chega num momento e fala assim, eu sou fraco, eu não dou conta de julgar meu próprio preso. (Grupo Educadores Sociais)

Um outro aspecto dessa relação com os Estados Unidos que mereceu observação e crítica dos participantes diz respeito ao momento em que a questão parece ter se tornado um problema para o país sul-americano. 
4. O que o Pablo fala é que eles atrapalham economicamente os Estados Unidos. Então parece que existe um pouco de relação de domínio dos Estados Unidos sobre a Colômbia.

1. E ao mesmo tempo parece que o presidente sente a necessidade de prestar contas aos Estados Unidos.

2. Querendo ou não, parece que o narcotráfico era um problema bem interno, mas ele extrapolou a Colômbia. E aí os Estados Unidos se sentem na obrigação de intervir. Como sempre.

3. É porque também estava interferindo a ele, né?

2. Mas é mais interno o problema.

4. Mas a impressão que eu tive é que os Estados Unidos só começam a intervir quando atinge ele. Quando mexe no dinheiro. (Grupo UFMG)

Para o grupo de Natal, era como se o narcotráfico não atrapalhasse em nada a população, e que o governo só começou a agir quando pressionado pelos Estados Unidos, quando o narcotráfico se tornou um problema econômico para esse país. Para o participante 4, "tudo é movimentado pelo econômico, tanto a política, a justiça, todos estão envolvidos economicamente". Ou seja, antes, parecia que o narcotráfico não era ruim e só se tornou assim pela pressão externa. O governo não agia porque se tinha sensação de que a população não era afetada por esse poder paralelo. Em síntese: o narcotráfico só começou a incomodar quando foi incômodo para os Estados Unidos.

Nesse sentido, é como se a narcotelenovela nos levasse à institucionalidade do Estado colombiano pelo discurso da intervenção norte-americana. As escolhas narrativas indicaram aos participantes que sem essa intervenção havia quase uma relação simétrica entre institucionalidade e narcotráfico, essa espécie de "paraestado". Se, para nós, o relato televisivo parte de escolhas feitas pelos realizadores sobre o que mostrar, o que contar - e, nesse caso, a opção parece ter sido mostrar como o narcotráfico está incrustrado nas estruturas sociais e políticas daquela sociedade-, os participantes parecem ter se engajado na narrativa compartilhando e 
identificando essas escolhas: as que trazem à tona a fraqueza institucional revelada pela presença do narcotráfico na vida daquele país.

A fragilidade do Estado também esteve presente no modo como os participantes identificaram a corrupção dos políticos em suas relações ocultas com os narcotraficantes. Relevante notar nas opiniões emitidas a esse respeito a forte mediação do contexto sócio-histórico e político do Brasil neste momento. A descrença nos políticos, na política formal, a corrupção latente e manifesta tanto no executivo quanto no legislativo, o comprometimento de bens públicos considerados como orgulho da nação brasileira, como é o caso da Petrobras, e as inúmeras operações em curso que investigam atos de corrupção, lavagem de dinheiro' ${ }^{9}$ desvio de verba pública, dentre outros diariamente visibilizados pela mídia, foram marcantes na leitura que os participantes fizeram da corrupção na política colombiana.

4. O Cartel de Medellín na Colômbia era o tal. Indiferente da política, indiferente de quem tivesse no poder. E contra um dos que tentaram fazer diferente, mais uma pessoa foi morta diante disso. É o que a gente percebe aqui no Brasil também, de certa forma. A gente tem inúmeros fatores que ajudam a gente a avaliar isso aí, tanto da questão política que nós vivemos hoje, com a dificuldade de inúmeros processos contra a Petrobras. E meio que se intercala essa combinação de que política e, vamos dizer assim, "bandidos", no geral, buscam um poder e usam de uma estratégia onde que eles conseguem envolver tanto político quanto bandido, junto.

1. Sempre eles tão ligados, né? Sempre junto um com o outro na corrupção, né? (Grupo Venda Nova)

Moderadora. Como vocês entendem o papel dos políticos?

5. O político está fazendo o papel dele; nosso congresso é assim, é feito de lobistas, só que não é declarado [...]. Eu não posso achar certo que ele está recebendo dinheiro de narcotraficante, opinião

9 No ano de 2014, a Polícia Federal divulgou a Operação Lava Jato, que investiga esquemas de lavagem e desvio de dinheiro que envolve a Petrobras — maior empresa estatal do Brasil— empreiteiras e políticos. A operação ainda está em andamento e sendo amplamente coberta pelas mídias. 
minha [...] Eu não concordo com isso, mas, infelizmente, o lobby funciona assim.

Moderadora. Você está se referindo a qual político?

5. De modo geral, todos os políticos.

3. É um pouco meio complexo ver a série porque, na Colômbia em 1985, você acaba vendo com a visão de hoje e com nossa realidade no Brasil, então na hora que você olha essa série, ela é muito próxima, quando falei da política é porque... envolve políticos com traficantes. Então a tendência é a olhar nossa realidade, então qual é essa nossa realidade? A política muito envolvida nos escândalos [...]. (Grupo Educadores Sociais)

A fragilidade do Estado envolveu também várias de suas instituições e não apenas o poder central. Destacamos o modo como os participantes qualificaram a instituição policial no conflito: a polícia foi considerada ausente. Ainda que outros adjetivos também tenham sido citados para identificá-la, tais como desorganizada, corrupta, fraca e ineficiente, a ausência foi a forma pela qual a maior parte dos grupos percebeu esse contingente ${ }^{10}$. "Ela aparece muito pouco", "totalmente deficiente", "parece que é ausente" e "em poucos momentos que a polícia agia de fato" sintetizam as impressões obtidas sobre a atuação do aparato policial. Dois aspectos parecem-nos relevantes. O primeiro, notado por uma participante do grupo dos educadores, se refere à relação de fidelidade dos sócios e demais empregados para com El Patrón, pela qual foi possível estabelecer um contraponto da falta de lealdade dos policiais para com os homens do poder público. Pelo vídeo, tornou-se claro que o pré-candidato à presidência Luis Carlos Galán foi assassinado em função da fragilidade na segurança que o cerco policial havia propositadamente armado para que os atiradores, a mando de Escobar, se infiltrassem no meio do público e atirassem no presidenciável. Para a participante, Pablo Escobar exercia certo fascínio sobre seus homens, além de

10 Após a realização de dois grupos, a equipe reuniu-se para avaliar se essa ausência do aparato policial não poderia estar ligada às escolhas das sequências que compõem o vídeo exibido aos grupos. Nesse sentido, foram acrescentadas mais algumas cenas que lançavam certa suspeita sobre a honestidade da atuação dos policiais e, ainda assim, a interpretação dos grupos seguintes foi a mesma: observaram a ausência da polícia. 
revelar-se sagaz, inteligente, impiedoso e estrategista. Essa questão da lealdade foi abordada por Rincón (2013) para delinear o que esse autor chamou de narcocultura.

A forma do narcotráfico é a produção da fusão de temporalidades, experiências, significados: cultura popular (celebração dos modos regionais e tradicionais de sobrevivência: a lealdade, o valor máximo), a contracultura perante a modernidade (religião e família acima da democracia e das instituições), pós-cultura (pastiche, onde todo símbolo joga sem referência ao seu valor de origem de classe, letra ou preferência). (p. 5, grifo nosso)

O outro aspecto que explica a ausência da polícia retoma o que foi exposto na primeira categoria e que diz de uma proposta da narrativa de trazer o problema do narcotráfico sob a ótica de sua inserção nas estruturas políticas e sociais colombianas, da fragilidade do Estado e da ausência da droga.

4. Eu não consegui identificar um personagem que fosse uma polícia; que estava tentando combater o negócio. Era mais uma coisa entre o presidente, entre as personagens ligadas à política e as personagens ligadas ao narcotráfico. (Grupo UFMG)

\section{Ver a Colômbia e pensar o Brasil... ou narcotráfico e microtráfico}

Conquanto as categorias tenham sido escolhidas como forma de apresentação dos resultados dos grupos, é preciso estar atento ao fato de que elas se mesclam e se cruzam em vários momentos. Nesse sentido, a narcopolítica, a fragilidade do Estado, a corrupção policial, a narrativa sobre as drogas novamente foram acionadas em muitos momentos em que os grupos partiram da narcotelenovela para pensar sobre os diversos relatos da questão das drogas no Brasil.

Em outras palavras, perceber o viés da produção colombiana possibilitou a percepção do foco das narrativas midiáticas produzidas no Brasil. Se na Colômbia tivemos a abordagem do narcotráfico, no Brasil vemos 
histórias do microtráfico. Em trabalho anterior (Rocha e Oliveira, 2014), realizamos uma investigação sobre a temática da droga no telejornalismo brasileiro e observamos que esses relatos podem levar-nos à conclusão de que o fenômeno das drogas quase sempre está associado aos espaços marginalizados e segregados de nossa sociedade - favelas, garimpos, prisões, fronteiras, aldeias indígenas - como se só ali se compartilhasse certos valores que não diriam respeito aos demais espaços sociais. Ademais, são narrativas centradas em dois aspectos preferenciais: no consumo como um problema a ser resolvido e na retórica da proibição. Investem e alimentam, desse modo, a "retórica proibicionista", na qual "o debate público entre nós ainda se pauta pela estreiteza proibicionista, que repudia e criminaliza o uso e o comércio de determinadas substâncias" (Simões, 2008, p. 15). Daí uma visualidade que enfoca usuários marginalizados e agentes repressivos e proibitivos. Quanto às narrativas de ficção seriada e fílmicas, assistir à Escobar, el patrón del mal permitiu aos participantes ver que as produções brasileiras não conseguem avançar em problemáticas mais de fundo. No caso destas últimas, soma-se, àqueles aspectos já mencionados, um significado preferencial: o foco nas disputas locais entre traficantes pelo controle das "bocas de fumo" ${ }^{11}$. Resultam dessas escolhas a representação de uma violência desmedida, a morte brutal e prematura dos envolvidos neste microtráfico, a luta quase sempre inglória das famílias na tentativa de salvar seus filhos desse mundo das drogas, o posicionamento dos policiais ante os bandidos, enquanto inimigos que desejam a morte recíproca, e uma visão conservadora e insinuante de que quem sustenta o tráfico é o usuário.

4. Em Paraísos Artificiais ${ }^{12}$ mostra o consumo, a coisa psicodélica. Pouco se discute quem levou aquilo pra lá, da estrutura daquilo.

2. No Pablo não mostra exatamente que a droga é proibida; ela não é o problema, o problema é o narcotráfico. [...] ele é o negócio, a parte econômica. (Grupo UFMG)

11 Locais de venda de drogas.

12 Filme brasileiro lançado em 2012 e dirigido por Marcos Prado. Tem como cenário uma festa na qual jovens consomem vários tipos de drogas e apresenta os efeitos do consumo sob uma visão psicodélica. 
Ao se referirem, sobretudo, aos produtos ficcionais tanto do cinema quanto da televisão, os participantes deram ênfase ao fato de que, nas narrativas brasileiras, há uma associação do tráfico ao espaço físico e social da favela ${ }^{13}$. As disputas pelo controle da venda da droga e as "batidas" policiais ocorrem nesses ambientes; são nas favelas que os jovens de classe média vão buscar droga para vender e para consumir. Para alguns participantes, parece que o tráfico está circunscrito à favela; como se os dois tivessem "nascidos” juntos. Já a narrativa colombiana, além de mostrar o conflito sob o olhar do traficante, trata da dimensão macro do fenômeno do narcotráfico, inclusive suas relações de e com o poder formalmente constituído. Segundo a narrativa, a vida de Pablo é perpassada por vários contextos: ele comanda seus negócios, vive em família, negocia com políticos e alcança as esferas de poder ao se tornar deputado. Na opinião dos grupos, o que vemos nas narrativas brasileiras é:

4. A venda...

6. Cidade de Deus...

4. Cidade de Deus, o Tropa de Elite [...] A realidade. Aquele filme retrata o que o nosso país vive a todo momento.

7. A droga, eu indo lá comprar.

6. $\mathrm{O}$ vendedor.

4. Você vê em todo lugar, já morei em São Paulo, em Brasília. Tá cheio de "filhinho de papai" vendendo droga.

1. E isso é uma coisa que você vê agora, tá descendo pro asfalto como dizem. "Filhinho de papai vendendo", não é só gente da favela como antigamente. (Grupo Venda Nova)

13 Estamos nos referindo ao processo de midiatização sofrido por esses espaços a partir do sucesso do filme Cidade de Deus (2001). Narrativas como essa trouxeram para as telas certo imbricamento entre a questão das drogas e o espaço da favela sob variados pontos de vista. No cinema, deram origem ao que se tornou conhecido como favela movie. Dentre alguns exemplos de ficção, podemos citar: Cidade dos Homens (2007); Tropa de Elite I (2007); Era uma vez (2008); Maré - Nossa História de Amor (2008); Tropa de Elite II (2010). Dos exemplos de documentários, temos: Ônibus 174 (2002); O Prisioneiro da Grade de Ferro (2004); Sou feia, mas estou na Moda (2005); Falcão, Meninos do Tráfico (2006); Jardim Ângela (2006). Na televisão, podemos citar as seguintes produções: Vidas Opostas (Record, 2006); Cidade dos Homens (Globo, 2002); Antonia (Globo, 2006) e A Lei e o Crime (Record, 2009). 
A única exceção feita foi ao filme Tropa de Elite 2, cujo enredo aborda também a formação das milícias e a corrupção estrutural na corporação policial e na política formal que maneja dados, enfoques e pessoas em ações inescrupulosas de defesa de interesses particulares e de enriquecimento ilícito. Ao comparar as duas narrativas [Tropa de Elite 2 e Escobar, el patrón del mal], um participante disse que:

0 [Tropa de Elite] 2 trata mais da parte política da droga no Brasil, assim, né, mostrando como que essas articulações se dão, não só na favela mas na política também. Como é uma coisa muito mais complexa, e é mais parecida com esse, [Escobar] assim, se aproxima mais nesse sentido. (Grupo Família BH)

Assim, Escobar, el patrón del mal possibilitou o gesto reflexivo por parte dos participantes no sentido de apreenderem criticamente que o tráfico de drogas é uma economia altamente rentável, que tem dimensões mais profundas e complexas e que muitas vezes não estão presentes em nossas narrativas sobre o tema. A reflexividade (Giddens, 1990), construída na recepção e discussão dos grupos, os fez notar que empresários, fazendeiros e negociantes que comandam o investimento, a produção e a lavagem de dinheiro ficam sob a proteção da invisibilidade. Entender os vínculos desse comércio, que gera lucros incalculáveis para ricos negociantes, com os setores informais comandado por um exército de empregados menores é fundamental para entender a problemática da droga no Brasil (Zaluar, 2004).

\section{Considerações finais}

O trabalho realizado junto aos grupos de discussão permitiu uma reflexão que trouxe à tona o pano de fundo da problemática do narcotráfico.

2. 0 tráfico é uma coisa horrível, mas é uma resposta à política, é uma resposta ao descaso da política e dos políticos com a população. Mas não defendendo de forma alguma 0 traficante [...] (Grupo Educadores Sociais)

Os produtos midiáticos representam uma importante mediação simbólica que filtra e enfatiza determinados temas, ao mesmo tempo que 
omite outros. A partir deles, são oferecidas perspectivas, modeladas imagens e criados contextos políticos e sociais (Rocha, 2006). Compreendemos que a televisão não mostra a realidade, mas sim a apresenta de forma própria, bem como acreditamos que o universo ficcional tem possibilidades tão próximas da realidade quanto outras. Nesse sentido, entendemos que as narrativas, inclusive as televisivas, têm essa potência de oferecer relatos que dão conta da vida social, conquanto o façam a partir de recortes e de escolhas feitas por quem as produz.

A investigação sobre os sentidos atribuídos pelos participantes dos grupos revelou-nos aspectos muito relevantes desse papel da televisão em nossas sociedades. Retomando as perguntas inicialmente apresentadas neste texto, vimos que a narrativa de Escobar, el patrón del mal nos faz ver os meandros de uma problemática instaurada de modo profundo na cultura e na política colombianas; nos faz ver que nossas sociedades latino-americanas — e não apenas a colombiana - desenvolvem, para o bem ou para o mal, suas estratégias próprias de entrada na modernidade, de atendimento às exigências de uma sociedade pautada pelo consumo e pelo afã do dinheiro fácil. As narrativas televisivas contribuem para nossa reflexividade e nos auxiliam na apreensão crítica dos fenômenos e dos acontecimentos de nossa própria realidade. A interação entre os participantes criou esse espaço de tal modo que em alguns momentos algumas opiniões eram revistas à luz de outras.

E, ao que parece, segundo a percepção das audiências investigadas nos grupos, a narcotelenovela repercute vários sentidos para além de certos dualismos que a crítica especializada, acadêmica, política e a própria mídia tendem a incorrer como, por exemplo, considerar narrativas como essas espetaculares e apologéticas do crime, além de fomentar uma imagem negativa da Colômbia. Em muitos casos, através dos meios de comunicação, magnificam-se o poder e o alcance da delinquência ligada ao narcotráfico, o que legitima um discurso de combate desapiedado contra essa delinquência, negligenciando-se todas as nuances do problema e, sobretudo, a complexidade de todos os atores e processos que o compõem. 
Assim, aproximar-se desse tema a partir da cultura popular e, no caso em tela, da telenovela, como Escobar el patrón del mal, o torna mais compreensível e próximo. Em nosso entendimento, as narcotelenovelas contribuem como uma espécie de narrativa contra-hegemônica ao exibir discursos locais que se contrapõem ao discurso oficial sobre o narcotráfico, ao revelar a fragilidade do Estado bem como as múltiplas representações da narcocultura.

\section{Referências}

Escobar, el patrón de mal. Caracol Televisión S.A. Distribuído por FM Entretenimento S.A.S.(C) 2012.

Giddens, A. (1990). As consequências da modernidade. São Paulo: Unesp.

Herlinghaus, H. e Walter, M. (1994). “¿Modernidad periférica” versus “proyecto de la modernidade"? Experiencias epistemológicas para reformulación de lo "pos" moderno desde América Latina. Em H. Herlinghaus e M. Walter (eds.), Posmodernidad en la periferia: enfoques latino-americanos de la nueva teoría cultural, 11-47. Berlim: Langer.

Lunt, P. e Livingstone, S. (1996). Rethinking the Focus Group in Media and Communication Research. Journal of Communication, 46(2), 79-98.

Martín-Barbero, J. (2004). Os exercícios do ver: hegemonia audiovisual e ficção televisiva. 2. ed. São Paulo: Editora Senac São Paulo.

Martín-Barbero, J. (2000). Televisión y literatura nacional. Em M. M. Jaramillo, B. Osorio e Á. I. Robledo (eds.), Literatura y cultura. Narrativa colombiana del siglo XX (p. 431-461). Ministerio de Cultura: Programa de estímulos a la creación y la investigación.

Martín-Barbero, J. (1987). Procesos de Comunicación y matrices de cultura: itinerario para salir de la razón dualista. México: Gustavo Gili.

Morgan, D. (1997). Focus Groups as Qualitative Research. Londres: Sage. 
Neira, L. F. e López de la Roche, F. (27 a 29 de novembro de 2014). La serie dramatizada Escobar: El patrón del mal. Ficción televisiva sobre el narcotráfico antioqueño y la guerra contra las drogas 1984-1993. Trabalho apresentado na IV Jornadas Internacionais de Problemas Latino-americanos, Unila e Unioeste, Foz do Iguaçu.

Rincón, O. (2013 jul.-dez). Todos temos um pouco do tráfico dentro de nós: um ensaio sobre o narcotráfico/cultura/novela como modo de entrada para a modernidade. MATRIZes, ano 7, 193-219.

Rincón, O. (2009 jul.-ago). Narco.estética y narco.cultura en narco.lombia. Nueva sociedade, 122, 147-163.

Robledo, J. (8 ago. 2012). Pablo Escobar tiene un álbum para niños en Medellín. BBC Mundo. Recuperado em http://www.bbc.com/ mundo/noticias/2012/08/120808_album_cromos_pablo_escobar_medellin_jr.shtml [Citado em 18 abril 2015].

Rocha, S. M. e Oliveira, L. F. (27 a 29 de novembro de 2014). Pensar a cultura das drogas: para pensar a sociedade e o papel da televisão. Trabalho apresentado no Simpósio 9 "Diálogos possíveis: a cultura nas ciências humanas latino-americanas”. IV Jornadas Internacionais de Problemas Latino-americanos, Universidade Federal da Integração Latino-Americana e Universidade Estadual do Oeste do Paraná, Foz do Iguaçu.

Rocha, S. M., Alves, M. L. C. e Oliveira, L. F. (2013 mai.-ago.). A história através do estilo: a Revolta da Vacina na telenovela Lado a Lado. Revista Eco-Pós [on-line], 1(16), 205-220.

Rocha, S. M. (2006 jan.-jun.). Debate público e identidades coletivas: a representação de moradores de favela na produção cultural da televisão brasileira. Intexto, 1(14), 1-21.

Roche, F. L. de la (16 de outubro de 2014). Comunicação, Cultura e Política na América Latina: elementos para análise cultural e político-cultural com- 
parado. Trabalho apresentado no Seminário Comunicação, Cultura e Política na América Latina: elementos para análise cultural e político-cultural comparado, Universidade Federal de Minas Gerais, Belo Horizonte.

Salazar JR. A. (1991). No nacimos p'a semilla. La cultura de las bandas juveniles en Medellín. 5. ed. Bogotá: Centro de Investigación y Educación Popular (Cinep).

Simões, J. A. (2008). Prefácio. Em B. C. Labate et al. (orgs.), Drogas e cultura: novas perspectivas (p. 13-21). Salvador: Editora da Universidade Federal da Bahia.

Thompson, K. (2003). Storytelling in Film and Television. Cambridge/Londres: Harvard University Press.

Zaluar, A. (2004). Integração perversa: pobreza e tráfico de drogas. Rio de Janeiro: Fundação Getúlio Vargas. 